\title{
MULHERES ARGELINAS REVOLUCIONÁRIAS E MULHERES NEGRAS BRASILEIRAS UNIVERSITÁRIAS: APROXIMAÇÕES EMANCIPADORAS
}

\author{
Andrea Maila Voss Kominek \\ andreakominek@yahoo.com.br \\ Universidade Tecnológica Federal \\ do Paraná (UTFPR), Curitiba, \\ Paraná, Brasil.

\section{Gilson Leandro Queluz} \\ gqueluz@gmail.com \\ Universidade Tecnológica Federal \\ do Paraná (UTFPR), Curitiba, \\ Paraná, Brasil. \\ Ivo Pereira de Queiroz \\ ivoaxe@gmail.com \\ Universidade Tecnológica Federal \\ do Paraná (UTFPR), Curitiba, \\ Paraná, Brasil
}

\section{RESUMO}

Frantz Fanon interveio na revolução argelina, particularmente, no âmbito da superestrutura, elaborando temas como o novo humanismo e os valores necessários à sociedade emancipada. Graças ao investimento na formação da consciência revolucionária, deixou um valioso legado consolidado nos textos que produziu. Parte de suas reflexões versaram sobre as mulheres argelinas revolucionárias e a contribuição histórica delas no processo de libertação daquele povo. Tendo em vista o acesso de mulheres negras brasileiras aos cursos superiores, especialmente nas áreas tradicionalmente ligadas ao mundo masculino, como os cursos associados às tecnologias e às engenharias, o presente texto tem como objetivo comparar e analisar a semelhança entre as ações das mulheres argelinas revolucionárias e das estudantes negras universitárias quanto ao seu potencial emancipador e ao impacto em suas respectivas sociedades. Num primeiro momento, o texto acompanha narrativas de Fanon sobre mulheres argelinas no contexto da luta de libertação. No próximo passo, contextualiza a realidade da mulher negra brasileira estudante de nível superior e as demandas históricas do gênero feminino negro. Finaliza o artigo com indicações de inspirações possíveis a serem auferidas das lutas das mulheres argelinas.

PALAVRAS-CHAVE: Argelinas revolucionárias. Consciência. Emancipação. Negras estudantes 


\section{INTRODUÇÃO}

Frantz Fanon (1925-1961), prestou relevantes serviços ao movimento de libertação da Argélia, particularmente por meio da produção de textos que foram publicados no jornal revolucionário El Moudjahid1. Aquele jornal servia para animar os militantes e manter a mobilização do povo. Por volta de 1959, os franceses desencadearam uma operação desmobilizadora, ao imitar o formato do El Moudjahid, porém com teor anti-revolucionário. Os jornais de contrainformação dos franceses passaram a ser distribuídos ao povo simultaneamente ao jornal da Frente de Libertação Nacional - FLN. Na primavera de 1959, Fanon pediu a seu assistente, o Dr. Geronomi - um colono francês que escolhera ser argelino -, se poderia substituí-lo durante um mês, no Hospital Charles Nicolle, atendendo-Ihe os pacientes, justificando-se:

“- Tenho que escrever um livro."

Realmente, um mês depois, Fanon reapareceu com o livro pronto, cuja narrativa homenageava aos argelinos em luta: $L$ 'an $V$ de la Révolution lgeriennez. (GEISMAR, 1972) O livro era uma resposta de Fanon aos agentes franceses da contrainformação. Suas páginas continham um relato vibrante, demonstrando que a luta de libertação estava entranhada no meio do povo. A narrativa do autor demonstra, com grande riqueza de detalhes, as transformações que a esperança da libertação por meio da luta revolucionária estava levando o povo argelino a um crescente processo de mobilizações e adesão consciente à luta. Uma das revelações refere-se ao protagonismo das mulheres argelinas revolucionárias. (GEISMAR, 1972) Tendo em vista o recente acesso de mulheres negras brasileiras aos cursos superiores, especialmente nas áreas tradicionalmente ligadas ao mundo masculino, como os cursos associados às tecnologias e às engenharias, o presente texto tem como objetivo comparar e analisar a semelhança entre as ações das mulheres argelinas revolucionárias e das estudantes negras universitárias quanto ao seu potencial emancipador e ao impacto em suas respectivas sociedades. Afinal, qual foi a gravidade da colonização francesa na Argélia, a ponto de levar o povo nativo a recorrer à luta armada? Teriam os franceses abandonado os pressupostos revolucionários dos direitos dos seres humanos, dos cidadãos, consagrados por seus antepassados nas lutas democráticas menos de um século antes da ocupação da Argélia? Acompanhemos a contextualização e caracterização do colonialismo francês na Argélia, bem como a exposição de Fanon, acerca do protagonismo das mulheres argelinas revolucionárias, antes de abordarmos o caso das mulheres negras brasileiras e os estudos universitários que realizam atualmente.

\section{COLONIZAÇÃO E VIOLÊNCIA}

A colonização francesa na Argélia perdurou de 1830 a 1961, período em que os franceses reprimiram a ferro e fogo quaisquer tentativas de reconhecimento do estatuto humano dos argelinos. A barbárie foi disseminada sobre a terra argelina. Homens e mulheres passaram a ser vigiados, caçados, torturados, guilhotinados, fuzilados, com artilharias complexas, aviões:

Trens carregados de militares franceses, a marinha francesa em águas de Argel e de Phillipeville, em ações de manobra e bombardeio, os 
aviões a reação, os milicianos que irrompem nos dormitórios e liquidam sem vacilar aos argelinos: tudo isso contribui para dar ao povo a impressão de que não está defendido nem protegido, que nada mudou e que os europeus podem fazer o que quiserem. (FANON, 1976, p. 38).

No momento em que se instaura o combate mortal entre os dois protagonistas, (colono $X$ colonizado), abre-se a via para que os últimos se tornem os primeiros. De acordo com Fanon (1979, p. 27) "exposta em sua nudez, a descolonização deixa entrever, através de todos os seus pólos, granadas incendiárias e facas ensanguentadas." Ele argumentou que descolonização é uma manifestação de violência da qual o colonizado em luta foi aluno: o grande professor de violência foi o colono, representante da metrópole colonial, "nos países capitalistas, entre o explorado e o poder interpõe-se uma multidão de professores de moral, de conselheiros, de 'desorientadores'". (FANON, 1979, p. 28)

Na colônia, a repressão executada pelo gendarme e pelo soldado, "a coronhadas ou com explosões de napalm" (FANON, 1979, p. 28) foi o mecanismo que o colono utilizou para a contenção física do colonizado. A tortura, o massacre e a fuzilaria estiveram sempre entre os procedimentos adotados para aniquilar valores, princípios e conceitos tradicionais das comunidades nativas. O colono criou um mundo maniqueísta: a cidade do branco, de um lado, com luxo e conforto e, de outro, a vila precária reservada ao colonizado. A escola dos filhos do colono e escola para indígenas, "a linha divisória, a fronteira, é indicada pelos quartéis e delegacias de polícia. Nas colônias o interlocutor legal e institucional do colonizado, o porta-voz do colono e do regime de opressão é o gendarme ou o soldado." (FANON, 1979, p. 28). O autor denunciou o aparato tecnológico para consumar a dominação: "nas colônias o estrangeiro vindo de qualquer parte se impôs com o auxílio dos seus canhões e das suas máquinas." (FANON, 1979, p. 2930).

Com a constante ação truculenta do colonizador, o colonizado tomou consciência da violência da colonização e se viu estimulado a destruir o programa recorrendo também ao uso da violência: "não se desorganiza uma sociedade, por mais primitiva que seja com tal programa se não se está decidido desde o início, isto é, desde a formulação mesma deste programa, a destruir todos os obstáculos encontrados no caminho." (FANON, 1979, p. 27) O autor apresentou os motivos que, entendia ele, evidenciavam as razões da violência de que o colonizado lançou mão, para se livrar do colono invasor. Estampou, por exemplo, o paradoxo entre o mundo do colono e do colonizado, apontando o quadro de miséria que marcava o espaço dos indígenas:

A cidade do colonizado, ou pelo menos a cidade indígena, a cidade negra, a édina, a reserva é um lugar mal afamado, povoado por homens mal afamados. Aí se nasce não importa onde, não importa como. Morre-se não importa onde, não importa de quê. É um mundo sem intervalos, onde os homens estão uns sobre os outros, as casas umas sobre as outras. A cidade do colonizado é uma cidade faminta, faminta de pão, de carne, de sapatos, de carvão, de luz. A cidade do colonizado é uma cidade acocorada, uma cidade ajoelhada, uma cidade acuada. É uma cidade de negros, uma cidade de árabes. (FANON, 1979, p. 30). 
Fanon (1979) analisou psicologicamente o colonizado. Qualificou-o de invejoso pois olhava com luxúria para a cidade do colono na intenção de tomar-lhe o lugar. Aquele invejoso desejava ter as coisas do colono, sentar-se à mesa, deitarse na cama, de preferência, com a mulher do colono. O argumento evoca uma afirmação de Marx e Engels, no Manifesto do Partido Comunista3. A descolonização é um processo radical. Rejeita a possibilidade de mesclar as duas zonas - a do colono e a do colonizado - Não! Desmanchar o mundo colonial significa destruir e enterrar a zona do colono. Eis, pois, a premissa para a violência do colonizado em luta:

A violência que presidiu ao arranjo do mundo colonial, que ritmou incansavelmente a destruição das formas sociais indígenas, que arrasou completamente os sistemas de referência da economia, os modos da aparência e do vestuário, será reivindicada e assumida pelo colonizado no momento em que, decidindo ser história em atos, a massa colonizada se engolfar nas cidades interditas. (FANON, 1979, p. 30)

Das páginas de Os Condenados Da Terra emerge minuciosa reflexão sobre a libertação colonial que longamente tem inquietado os espíritos conservadores, particularmente quando Fanon passa a investigar o sentido e o papel da violência. Primeiramente, encarou-a como instrumento do conquistador europeu. Mais tarde, identificando danos que esta causou entre povos colonizados, apresentoua como terapia, meio de cura da psique das pessoas atormentadas pela colonização.

\section{MULHERES ARGELINAS REVOLUCIONÁRIAS: SUBVERTENDO COSTUMES}

O texto de Fanon (1979) registra a crescente tensão produzida pela ação dos franceses que não economizavam aparatos bélicos e ideológicos para a subjugação, para exercerem o pleno controle da Argélia e do povo argelino. Entrementes, os argelinos, que nada mais tinham a perder, passaram à contraofensiva, desencadeando a revolução libertadora. O Movimento de Libertação da Argélia4 estendeu-se, ganhando dimensão nacional, cuja meta ficava cada vez mais evidente para o povo. As pessoas, na esperança pela libertação, aos poucos foram assumindo atitudes de violência bélica, mergulhando nas águas revoltas da luta armada. Tais ações, por sua vez, passam a gerar mudanças radicais nos parâmetros culturais vividos até então. Com efeito, notou Fanon(1979), os franceses levaram os argelinos ao limite do suportável:

O desenvolvimento da luta de Libertação nacional, o caráter progressivamente total da repressão que causa graves traumatismos ao grupo familiar: um pai sequestrado nas ruas em companhia de seus filhos, despido ao mesmo tempo que eles e torturado sob seus olhos; fraternidade viva e aguda de homens com as costas nuas e ensanguentadas; esposos detidos, internados, encarcerados; nesta situação, as mulheres devem encontrar os meios de impedir que as crianças morram de fome.(FANON, 1976, p.77)

Dentre as mudanças sociais e culturais decorrentes da luta armada, encontrafrancesa e o aumento da luta revolucionária, a família argelina foi sofrendo 
transformações. Os valores tradicionais tornavam-se insuficientes para explicar e fazer frente à violência imposta pelos franceses. O pai, autoridade maior da família, a princípio, evitava o envolvimento no combate aos colonos e operava para dissuadir o filho de participar da resistência. As filhas, subordinadas aos parâmetros da tradição, deveriam seguir os hábitos seculares: à medida que atingiam a puberdade, assumiam a conduta do recato, da ocultação do corpo e do distanciamento do pai e do irmão. Orientadas pela mãe, estariam prontas para o matrimônio até os dezesseis anos de idade. Analfabetas e sem trabalho, eram mantidas afastadas dos conflitos fora da residência. (FANON, 1976). Contudo, notou Fanon (1976), o colonialismo não poupou as mulheres argelinas. Ao lado da tortura e do assassinato dos homens, os franceses assaltavam as casas, sequestravam, torturavam, estupravam e assassinavam as mulheres. Como ressaltou Fanon (1980, p. 73), a tortura era um "estilo de vida".

As mulheres argelinas, particularmente as jovens, diante do frenesi suscitado pela atmosfera da luta de libertação, permaneceram resignadas ao papel que a tradição lhes determinava? E o pai, porta-voz do dogmatismo cultural, teria sido desafiado pela filha, interpelada pelo ímpeto revolucionário? Como foi a transição da família argelina para os novos tempos?

Fanon (1976, p. 85) descreveu e explicitou a crise que fez surgir a nova mulher argelina:

As mulheres na Argélia, a partir de 1955, começam a descobrir seus próprios modelos. De fato, na sociedade argelina circula a história de muitas mulheres que, nos djebels, ou nas cidades morrem e são encarceradas para que nasça a Argélia independente. Essas mulheres militantes encarnam os sistemas de referência em torno dos quais a imaginação da sociedade feminina da Argélia entrará em ebulição. A mulher-para-o-matrimônio desaparece progressivamente e cede seu lugar à mulher-para-a-ação. A jovem é substituída pela militante e a mulher indiferenciada pela irmã.

Deveras, o relato de Fanon (1976, p. 85-86, grifos do autor) traça um quadro social inimaginável até então, posto o ímpeto com que as moças adentravam as forças combatentes da Frente de Libertação Nacional (FLN):

As células femininas da FLN recebem adesões em massa. A impaciência das novas recrutas é tal que com frequência põem em perigo as tradições da total clandestinidade. Os responsáveis veemse obrigados a frear seu o que trabalham por um mundo novo. Desde o momento em que se incorporam à luta, solicitam as missões mais perigosas. Apenas a formação política que lhes é ministrada as levará progressivamente a não conceber a luta somente em sua forma mais explosiva. A jovem argelina aprende então a conter sua impaciência e a mostrar suas qualidades insuspeitadas de calma, de sangue frio e decisão.

Fanon (1976) apresenta as proezas das mulheres argelinas, relatando situações dos campos de batalhas, as astúcias, coragem e desprendimento delas. Toma o cuidado de informar que as moças enfrentavam as demandas em condições de igualdade com os homens, com os quais compartilhavam alojamentos, criando novos parâmetros de relações intersexuais. E a relação da filha com o pai, antigo guardião da moral e dos costumes? Como se daria o 
reencontro da moudjahidini com o núcleo familiar de onde veio? Responde o próprio Fanon (1976, p. 86-87):

Algumas vezes, a jovem, com novos documentos de identidade, volta à família. Então tem a oportunidade de contar ao pai e à mãe as ações prodigiosas que todos os dias ocorrem no djebel. Mostra fotografias, fala de seus chefes, de seus irmãos, da população, dos feridos, dos prisioneiros franceses. Olha o pai, senta-se diante do pai, lhe fala e não se envergonha.

E o pai, como reage? Envergonha-se, revolta-se? Diz Fanon (1976, p. 87):

E o pai não desvia o olhar (da filha), e tampouco se envergonha. Ao contrário, sente uma felicidade real de voltar a encontrar sua filha, de ver que sua nova personalidade brilha no lar, e não se aborrece que sua filha fale em voz alta e, de modo algum, surge em sua mente a ideia de que a mulher deve calar-se.

Fanon (1976, p. 86) acrescenta que a abertura do pai perante a nova mulher em que sua filha se transformou não se questionava, com patrulhamentos de ordem moral e sexual:

Durante os três dias que dura a licença, o pai não sente a necessidade de questionar sua filha sobre sua conduta moral na guerrilha. Este silêncio não significa desinteresse ou resignação frente à virgindade de ontem. $O$ fato é que o pai mede $o$ avanço imenso da sociedade $e$ essas questões que não abandonaram seu espírito se revelam simplesmente como inoportunas e secundárias. A jovem argelina que surge no céu agitado da História leva seu pai a um tipo de mutação, de desprendimento de si mesmo.

Fanon (1976, p. 86) interrompe a narrativa tecendo uma interpretação do sentido das novas condutas, perspectivando o novo momento, os costumes tradicionais e o sentido das mudanças, apoiado sobre o ideal da liberdade conquistada pela luta do povo. Para o pai, perguntar "se 'é séria' uma mulher que cotidianamente enfrenta a morte, seria grotesco e ridículo. A jovem militante, ao assumir um novo comportamento, escapa às coordenadas tradicionais. Os antigos valores, as fobias estéreis e infantis, desaparecem."

As lutas das jovens argelinas, relatadas por Fanon (1976), teriam ocorrido entre os anos de 1954 e 1959. Embora cerca de sessenta anos separem a escrita deste trabalho e a luta daquelas mulheres revolucionárias, é possível estabelecer aproximações importantes entre as demandas, ações e desafios que elas enfrentaram na Argélia e o estado de coisas a serem combatidas pelas mulheres estudantes negras da Diáspora Africana no Brasil, especialmente aquelas que frequentam cursos superiores e identifiquemos os desafios que enfrentam.

\section{CONTEXTO HISTÓRICO CULTURAL DAS MULHERES NEGRAS BRASILEIRAS: HERANÇA AMARGA}

A diáspora negro-africana no Brasil, motivada por questões alheias à escolha de seus habitantes que foram caçados, escravizados e transportados em condições degradantes para o "Novo Mundo", possui ainda hoje consequências em todos os âmbitos da sociedade brasileira. 
A diáspora africana no Brasil é resultado de ambiciosos e assustadoramente eficientes planos imperialistas europeus de conquistar, através do escravismo criminoso não apenas matérias primas deste rico continente, mas também braços fortes e mentes sábias dos habitantes locais. Trata-se do processo conhecido como triangulação comercial ${ }^{5}$.

Segundo a ótica colonialista europeia, o processo de escravização dos negros africanos constituía um negócio perfeito: exploração das riquezas naturais em território africano, apropriação de conhecimentos científicos e culturais de seus habitantes além, é claro, da venda de "mercadorias humanas" para uso no além mar. Este procedimento econômico durou aproximadamente 4 séculos e representou, por um lado, a degradação das culturas e sociedades locais do continente africano e, por outro, a chegada no Brasil, de uma nova realidade, novas culturas.

Os negros escravizados, vendidos e negociados como mercadoria, como mão de obra barata e eficiente, como animais de carga, eram, no entanto, HUMANOS, ainda que não fossem assim reconhecidos. Participavam da humanidade, ou seja, eram portadores de riquíssimo repertório cultural que se expressavam nos valores, idiomas, cultura, conhecimentos, hábitos, visões de mundo, religião.

Assim, sendo humanos, não bastava tranca-los e obriga-los ao trabalho pois o humano possui uma peculiaridade interessante: quer ser livre e lutará por isto com todos os recursos que dispuser. Era preciso fortalecer o processo de escravidão criminosa através, principalmente das superestruturas representadas pelas Leis e pela Religião.

As legislações e a doutrina católica constituíram-se em instrumentos superestruturais, isto é, por reunirem recursos ideológicos, que atuaram no âmbito da cultura e agiram como formatadores das mentes e dos corações das pessoas. Os mesmos fatores superestruturais, exercendo função semiótica, operaram também como codificadores sociais que impregnaram as instituições, criando os pressupostos da dominação. O reflexo contemporâneo de tal movimento de deculturação, que desafricanizava os negros e, simultaneamente, de aculturação que os europeizava ajuda a compreender as relações sociais no Brasil racista que trata o negro como um cidadão de segunda classe. São estes os pressupostos que tornam o povo negro alvo dos olhares de suspeição, e da violência de todos os níveis, de modo a transformá-lo em coletividades socialmente excluídas. (QUEIROZ, KOMINEK, 2016, mimeo).

Era preciso fortalecer os laços da escravidão criminosa, naturalizá-la e justifica-la. Era preciso não apenas ser 'o senhor', mas principalmente ensinar, adestrar quem até pouco tempo era livre, a ser, agora, 'o escravo', 'domesticado'. Ser 'o bom negro', 'domesticado' passa a significar assumir e submeter-se ao discurso dominante.

A força física, a violência e os grilhões tiveram consequências devastadores em corpos, famílias e mentes, porém, o discurso ideológico que sustentava o Brasil escravocrata foi e é ainda mais devastador, uma vez que seus efeitos são sentidos até os dias de hoje pelos descentes africanos, através dos diversos processos de exclusão e racismo por eles sofridos. Trata-se de uma herança amarga, tragada 
diariamente pelas novas gerações de afrodescendentes. No Brasil escravocrata, a referência, o padrão de "bem-sucedido" assumia um perfil fortemente definido: homem, branco, europeu, heterossexual. Assim, todos e todas, assim como seus descendentes, que neste perfil não se encaixavam, encontravam-se excluídos. 0 que explica, por exemplo, a busca pela branquitude ${ }^{6}$, tão comum em nosso país.

Dentre as excluídas, encontra-se um grupo que sofre uma tripla exclusão: por serem Mulheres, Negras e Pobres. A próxima seção tratará da situação destas Mulheres, Negras, quando chegam à Universidade, um espaço, tradicionalmente, não destinado a elas.

\section{MULHERES NEGRAS BRASILEIRAS E A CONQUISTA DE SEU ESPAÇO}

Em decorrência de todo o processo de alienação promovido pelos instrumentos ideológicos estruturais da sociedade colonial brasileira que subsistem na atualidade, as mulheres negras sofrem exclusões sobrepostas: por serem mulheres e por serem negras. A própria concepção e percepção social do corpo feminino é uma construção histórica, cultural e social:

As contradições que as mulheres enfrentam diante do desafio de participação política e social em termos de igualdade, mas com expectativas diferenciadas, continua fazendo parte do cotidiano das mulheres. Precisamente porque o corpo das mulheres é também uma construção social (...) a expropriação da corporalidade em favor de interesses econômicos, sociais e culturais. (DEIFELT, 2002, p. 261).

A consequência direta de toda esta forma de manipulação ideológica é o racismo, em todos os seus nuances e formas. Um racismo que se manifesta cotidianamente na vida das mulheres negras de diversas formas, dentre elas: 1- na condenação à solidão e em a não constituir família, decorrente da busca pelo ideal do branqueamento por possíveis, mas improváveis parceiros, brancos ou negros; 2- no tratamento estigmatizado e pré-concebido às suas tentativas de inserção social; 3-nas barreiras profissionais, dissimuladas por anúncios de "boa aparência", que em realidade representam muitas vezes um racismo oculto; 4- na sua não auto identificação com as imagens de mulheres veiculadas nas grandes mídias e agências de publicidade; 5 - além da maior das dores, violência sexual, muitas vezes não reconhecida, pelo senso comum nem pelo Estado, contra suas filhas, estatisticamente em número superior ao das brancas, além do genocídio sistemático de seus filhos. ${ }^{7}$ Enfim, a mulher negra está submetida a todos os desafios comuns a qualquer mulher em uma sociedade machista e majoritariamente masculina nos círculos de poder, porém acrescidos dos desafios da questão racial. A consequência costuma ser, mais uma vez, a tentativa desta mulher, por "adequar-se" ao padrão normativo, por 'branquear-se', buscando tornar-se um 'não-eu', mas uma mímica do modelo da mulher branca, imposto pela sociedade. Tal situação explicaria, por exemplo, o fato de o Brasil ser o país de maior consumo de produtos de beleza para cabelos, com especial ênfase em produtos "alisadores", "antivolume", "antifriz", como comprova um rápido passeio pelo setor de perfumaria de qualquer mercado nacional, dos mais simples e modestos de qualquer periferia, aos mais luxuosos e gigantescos dos grandes centros comerciais. As mulheres, especialmente as negras, tornaram-se reféns de um padrão de beleza irreal, desnecessário, inexistente, inatingível, injusto e cruel. ${ }^{8}$ 
Neste contexto injusto, desigual, excludente e doentio, insere-se a personagem foco deste trabalho: a mulher negra acadêmica. No Brasil, através do processo de "convencimento ideológico" e da pseudo "naturalização" das desigualdades, o racismo atua em eixos estruturantes de exclusão social. Esta lógica se reflete em todos os âmbitos institucionais e chega à universidade, ambiente no qual as mulheres, especialmente as mulheres negras, vivenciam as situações mais desfavoráveis.

Embora a democratização do acesso ao ensino superior tenha sido estimulada por uma série de políticas públicas, muito caminho precisa ainda ser construído e trilhado para que se atinja a igualdade de gênero e racial. Segundo o Dossiê Mulheres Negras: retrato das condições de vida das mulheres negras no Brasil9, existe uma grande diferença de escolarização entre mulheres brancas e negras, sendo 13,9 pontos percentuais a mais para as mulheres brancas. Se comparadas aos homens negros, a diferença sobe para 17,1 pontos percentuais em favor dos homens. Assim, em uma concorrência de currículo, por exemplo, é provável que a mulher negra seja a última opção a ser escolhida para a vaga. Em tempos de crise econômica, uma realidade ainda mais assustadora.

O Dossiê evidencia ainda que, a despeito do crescimento das taxas de escolarização apontado, a presença de mulheres e homens brancos ainda é muito superior à de mulheres e homens negros: Em 2008, a distribuição percentual de estudantes no ensino superior apresentava os seguintes índices: homem branco: 32\%; homem negro/pardo: 11\%; mulher branca: 38\%; mulher negra/parda: $19 \%$.

Apenas as informações sobre taxa de escolaridade, no entanto, não são suficientes para uma explicação acerca da persistência das desigualdades no ensino superior. Além dos dados quantitativos, há ainda que se considerar situações específicas vivenciadas pelas mulheres no meio acadêmico, majoritariamente classista, branco e masculino.

Muitos são os desafios a serem superados pelas mulheres, pois mesmo aquelas que ingressam na universidade (em menor número, comparativo às mulheres brancas), sofrem grande resistência e preconceito direcionados às acadêmicas negras, especialmente as que utilizam instrumentos de ação afirmativa, como as cotas raciais. É o que aponta a pesquisadora CORDEIRO (2008, p. 26) "Muitas professoras, ainda que integrem grupos minoritários, sejam negros, indígenas ou LGBT, se auto invisibilizam, não assumindo para si tal condição. Essa postura acaba se refletindo entre os alunos, contribuindo para a discriminação". Salienta, ao final do estudo, no entanto, que: "o número crescente de mulheres negras na UEMS é uma esperança para uma conscientização institucional de que esse público deve ter amparo na Universidade." (CORDEIRO, 2008, p. 79).

\section{CONSIDERAÇÕES FINAIS}

A modo de conclusão: aproximação entre as argelinas revolucionárias e as universitárias negras brasileiras.

Qual seria então a aproximação possível entre as argelinas revolucionárias apresentadas por Fanon (1975) e as mulheres negras universitárias brasileiras? Pode-se afirmar que ambas representam uma ruptura do status quo de suas 
respectivas sociedades e ambas lutam por seu reconhecimento e garantia da própria individualidade.

Se as argelinas revolucionárias não poderiam voltar aos seus lares sem que uma grande transformação interna Ihes tenha ocorrido e, consequentemente, sem abalar as 'tradições' e transformar suas realidades, igualmente a chegada das mulheres negras ao ambiente acadêmico universitário provoca transformações, internas e externas e, consequentemente, desconforto expresso, normalmente, através de atos racistas e machistas, por parte de colegas e professores, pais, parentes e amigos.

É comum ouvir, por exemplo, depoimentos de mulheres negras que afirmam dedicarem-se aos estudos mais que seus colegas e serem cobradas muito mais do que eles. A dedicação e a cobrança, no entanto, não resultam em reconhecimento. Recebendo, seja em forma de nota, prestígio ou oportunidades, resultados normalmente inferiores a seus colegas homens e a suas colegas brancas.

Assim como o ambiente acadêmico, o ambiente doméstico também é alterado pelo ingresso das mulheres negras na universidade. Muitas delas são a primeira geração da família a frequentar a universidade, de onde trazem perspectivas e valores diferentes dos familiares gerando, por vezes, choques e embates geracionais. $\mathrm{O}$ fato de as universidades brasileiras serem tradicionalmente elitistas, brancas e eurocêntricas, apenas contribui para que ocorra o estranhamento em ambos os ambientes: acadêmico e doméstico! Trata-se de uma realidade de racismo, exclusão, estranhamento, resistência e superação. Uma realidade, no entanto, que pode e deve ser transformada.

As contradições que as mulheres enfrentam diante do desafio de participação política e social em termos de igualdade, mas com expectativas diferenciadas, continua fazendo parte do cotidiano das mulheres. Precisamente porque o corpo das mulheres é também uma construção social (...) a expropriação da corporalidade em favor de interesses econômicos, sociais e culturais. (DEIFELT, 2002, p. 261).

Para que esta realidade seja transformada, é necessário que seja conhecida. É fundamental o desenvolvimento de estudos que permitam mapear os detalhes, características e efeitos do ingresso das mulheres negras nas universidades. É preciso estar consciente das escolhas e ações institucionais. É preciso lembrar, a cada momento, que a subjetividade, o imaginário religioso, social e cultural determina ou, no mínimo, influencia, o que costuma-se chamar, de forma naturalizada, de 'senso comum'. Tal senso comum constitui, no entanto, uma construção histórica, permeada de valores e escolhas ideológicas. Se trata, portanto de um recorte da realidade, de escolhas e manipulações ideológicas, de algo "aprendido" e "ensinado", trata-se, igualmente, de algo que pode ser "transformado", "desaprendido". Uma tarefa sobre a qual movimentos negros e feministas costumam e precisam debruçar-se. O caminho seguro para superar o contexto de racismo estrutural e institucional nacional, são a elaboração e desenvolvimento de pesquisas que gerem dados, analisem e busquem compreender a realidade. Para agir e transformar, é preciso conhecer.

Nossas acadêmicas negras constituem, assim, uma nova classe de revolucionárias. Revolucionárias na luta contra o racismo. Suas armas não são bélicas, mas conhecimento, presença, ocupação de espaço, denúncia e 
posicionamento político. Revolucionárias que, ao lutarem por seus espaços, em suas próprias realidades e vida, acabam por influenciar e transformar a realidade que as circundam. Uma mudança que, felizmente, não terá volta. 


\title{
ALGERIAN REVOLUTONARY WOMEN AND BRAZILIAN BLACK UNIVERSITY WOMEN: EMANCIPATORY APPROACHES
}

\begin{abstract}
Frantz Fanon intervened on the Algerian revolution, particularly, within its superstructure, elaborating themes as the new humanism and the necessary values to the emancipated society. Thanks to the investment on the formation of the revolutionary consciousness, he left a valuable consolidated legacy in the texts produced by him. Part of his reflections versed about the Algerian revolutionary women and their historical contribution to the progress of freedom of its people. Bearing in mind the accessibility of Brazilian black women to degree courses, especially on the traditional areas linked to the man's world, as the courses associated to the technology and to the engineering, the present article seeks to analyze and compare the similarities between the actions of the Algerian revolutionary women and the black university students about their emancipatory potential and the impact on their societies. Initially, the article follows Fanon's narrative about the Algerian women in the liberation struggle scenario. In the next step, shows the reality of the Brazilian black student women, with higher education, and the historical demands of the black female gender. The article ends with Indications of possible inspirations to be drawn from the struggles of Algerian women.
\end{abstract}

KEYWORDS: Revolutionary Algerians. Consciousness. Emancipation. Black students. 


\section{NOTAS}

${ }^{1}$ As traduções deste termo incluem, dentre outros: soldado sagrado; mártir; combatente; militante; membro de um exército de libertação de um país. $\mathrm{Na}$ literatura produzida por Fanon, aparecem moudjahid e moudjahidini, para se referir ao soldado do exército revolucionário e à mulher-soldado. Na Argélia há um jornal eletrônico com este nome - http://www.elmoudjahid.com/

${ }^{2}$ Mais tarde, o livro foi renomeado, passando a se chamar Sociología de una revolución.

3 "Horrorizai-vos por querermos [...] a propriedade privada. [...] Numa palavra, censurai-nos que quei-ramos [...] vossa propriedade. Pois é isso [...] que queremos". (MARX; ENGELS, URSS, 1987, p. 49)

${ }^{4}$ Movimento de Libertação da Argélia da Colonização Francesa se estendeu de 1830 a 1961.

${ }^{5} \mathrm{O}$ comércio triangular consistiu em embarcações saídas do litoral brasileiro que descarregavam produtos tropicais nos portos de Portugal, Holanda e Inglaterra. Em seguida, deslocavam-se para o litoral africano levando manufaturas que utilizavam para barganhar por gente aprisionada. Tais prisioneiros abarrotavam os porões dos navios, tumbeiros, e eram transportados para o Brasil. As/os sobreviventes daquelas terríveis semanas de fome, calor, imundície e castigos, eram leiloados junto aos proprietários de terras. (NOVAIS, 1989)

${ }^{6}$ A branquitude entendida como uma construção sócio-histórica produzida pela ideia falaciosa de superioridade racial branca, e que resulta, nas sociedades estruturadas pelo racismo, em uma posição em que os sujeitos identificados como brancos adquirem privilégios simbólicos e materiais em relação aos não brancos." (SCHUCMAN, 2012, p. 7). A respeito da cultura racista, (BENTO 2003, p. 25-26), explicita que, "na verdade, quando se estuda o branqueamento constatase que foi um processo inventado e mantido pela elite branca brasileira, embora apontado por essa mesma elite como um problema do negro brasileiro. Considerando (ou quiçá inventando) seu grupo como padrão de referência de toda uma espécie, a elite fez uma apropriação simbólica crucial que vem fortalecendo a autoestima e o autoconceito do grupo branco em detrimento dos demais, e essa apropriação acaba legitimando sua supremacia econômica, política e social." (...) Assim, o que parece interferir neste processo é uma espécie de pacto, um acordo tácito entre os brancos de não se reconhecerem como parte absolutamente essencial na permanência das desigualdades raciais no Brasil."

${ }^{7}$ A polêmica gerada pela reportagem de Juliana Linhares da Revista Veja, sobre a matéria da hoje Primeira Dama brasileira Marcela Temer, veiculada em 18 de abril de 2016, ilustra o que César (2010) e Foucault (1977) discorreram em seus textos sobre as sexualidades, produção de sujeitos ideais e controle dos corpos, imputando papéis bem definidos para cada um. De forma que se propaga a ideia geral de que sujeitos fora desses papéis definidos podem ser vistos pela sociedade como abjetos. Embora não haja problema algum em ser recatada e do lar, a polêmica gira em torno da imposição que toda a categoria mulheres deva ter esses mesmos atributos para serem consideradas respeitáveis pela sociedade. Além do mais, de que tipo de recato estamos falando? E que lar é esse? Outro elemento pertinente diz respeito à bela, por ser uma construção subjetiva a cada indivíduo 
e/ou grupo social. Têm-se, assim, a criação desse estereótipo bela, recata e do lar de como uma mulher brasileira deve ser fortemente contestada pelos movimentos sociais/feministas. 0 link da matéria da revista: $\leq$ http://veja.abril.com.br/brasil/marcela-temer-bela-recatada-e-do-lar/>.

${ }^{8}$ Sobre os processos de resistência a estes padrões estéticos eurocêntricos ver: MATTOS, Ivanilde Guedes. Estética afro-diaspórica e o empoderamento crespo. Pontos de Interrogação. Alagoinhas: Bahia, UNEB, v. 5, n.2, 2015, p. 37-53.

${ }^{9}$ Dossiê mulheres negras: retrato das condições de vida das mulheres negras no Brasil / organizadoras: Mariana Mazzini Marcondes ... [et al.].- Brasília : Ipea, 2013. $160 \mathrm{p}$.

\section{REFERÊNCIAS}

BASTOS, João Augusto de Souza Leão de Almeida. (Org.). Tecnologia \& Interação: publicação do Programa de Pós-Graduação em Tecnologia - PPGTE/CEFET-PR. Curitiba: CEFET-PR, (Coletânea "Educação e Tecnologia” CEFET-PR), 1998.

BENTO, Maria Aparecida Silva (2003). Branqueamento e Branquitude: Psicologia social do Racismo. Petrópolis: Vozes

CORDEIRO, Maria José de Jesus Alves. (2008) Negros e Indígenas Cotistas da Universidade de Mato Grosso do Sul. São Paulo: PUC. Tese. Universidade Católica de São Paulo.

DEIFELT, Vanda. (2002) O corpo e o cosmo. In: TIBIRI, Macia, MENEZES, Magali e EGGERT, Elda. As mulheres e a filosofia. São Leopoldo, UNISINOS.

MARCONDES, Mariana Mazzini; PINHEIRO, Luana; QUEIROZ, Cristina; QUERINO, Ana Carolina; VALVERDE, Danielle. Dossiê mulheres negras: retrato das condições de vida das mulheres negras no Brasil. Brasília: IPEA, 2013. Disponível em:

http://www.ipea.gov.br/portal/index.php?option=com_content\&view=article\&id =20978. Acesso em: 15/10/2016.

FANON, Frantz. Pele negra, máscaras brancas. Porto: Paisagem, 1975.

FANON, Frantz. Sociología de una revolución. 3. ed. Traducción de Víctor Flores. México 13, D.F.: Ediciones Era, 1976.

FANON, Frantz. Os condenados da terra. 2. ed. Tradução de José Laurênio de Mello. Rio de Janeiro: Civilização Brasileira, 1979.

FANON, Frantz. Em defesa da revolução africana. Lisboa: Livraria Sá da Costa Editora, 1980.

FREIRE, Paulo. Pedagogia da autonomia: saberes necessários à prática educativa. 6. ed. São Paulo: Paz e Terra, 1997.

GEISMAR, Peter. Fanon. Traducción de Marta Mastrogiacomo. Buenos Aires: Granica, 1972.

FLACSO. Mapa da Violência. Disponível em:

http://www.mapadaviolencia.org.br/mapa2015_mulheres.php. Acesso em: 15/10/2016. 
MARX, Karl; ENGELS, Friedrich. Manifesto comunista. URSS: Edições Progresso, 1987.

MATTOS, Ivanilde Guedes. Estética afro-diaspórica e o empoderamento crespo. Pontos de Interrogação. Alagoinhas: Bahia, UNEB, v. 5, n.2, 2015.

NOVAIS, Fernando A. Portugal e Brasil na crise do antigo sistema colonial (17771808), São Paulo, Hucitec, $5^{\circ}$ ed, 1989.

QUEIROZ, Ivo, KOMINEK, Andrea. Ontologia negativa do ser negro. Virada Filosófica 2016 - Curitiba, 2016.

SCHUCMAN, Lia Vainer. Entre o "encardido", o "branco" e o "branquíssimo". Raça, hierarquia e poder na construção da branquitude paulistana. São Paulo: banca de teses, USP, 2012.

Recebido: 01 de dezembro de 2016

Aprovado: 22 de março de 2017.

Como citar:

KOMINEK, Andrea Maila Voss.; QUELUZ, Gilson Leandro; QUEIROZ, Ivo Pereira de. Mulheres Argelinas Revolucionárias e Mulheres Negras Brasileiras Universitárias: Aproximações Emancipadoras. Cad. Gên.Tecnol., Curitiba, v. 10, n. 35, p. 25-39, jan./jun. 2017.

Correspondência:

Andrea Maila Voss Kominek

Av. Sete de Setembro, 3165, CEP 80230-901, Curitiba, PR, Brasil

Direito autoral:

Este artigo está licenciado sob os termos da Licença Creative Commons-Atribuição 4.0 Internacional.

(c) (1) 